\title{
Contato precoce pele a pele entre mãe e filho: significado para mães e contribuições para a enfermagem
}

\author{
Precocious skin-to-skin contact between mother and child: meanings to mothers and contributions for nursing \\ Contacto precoz piel a piel entre la madre y el niño: significado para las madres y contribuciones para la enfermería
}

\author{
Thaís Alves Matos', Morgana Stefani de Souza', Evanguelia Kotzias Atherino dos Santos', \\ Manuela Beatriz Velho', Eli Rodrigues Camargo Seibert", Nezi Maria Martins" \\ 'Universidade Federal de Santa Catarina. Departamento de Enfermagem. Florianópolis, SC \\ "Universidade Federal de Santa Catarina. Hospital Universitário. Florianópolis, SC
}

Submissão: 10/09/2009

Aprovação: 09/11/2010

\section{RESUMO}

Tratou-se de uma pesQuisa convergente-assistencial, realizada numa maternidade da Região Sul do Brasil entre abril e maio de 2009 , objetivando compreender o significado do contato precoce pele-a-pele mãe-filho para o ser-mãe, identificar características do estabelecimento desse contato e contribuições da enfermagem. Os dados foram coletados pela observação participante e entrevista, com nove mães, identificando-se Quatro categorias: a) orientações acerca do contato pele-a-pele precoce mãe-filho antes do nascimento; b) estabelecimento do contato precoce pele-a-pele mãe-filho; c) significado do contato pele-a-pele precoce mãe-filho para o ser-mãe; e d) contribuições da enfermagem no estabelecimento do contato precoce pele-a-pele mãe-filho. Conclui-se Que o significado do contato precoce mãe-filho atribuído pelas mães é positivo, e a contribuição da enfermagem no estabelecimento desse contato é significativa.

Descritores: Parto; Parto humanizado; Aleitamento materno; Enfermagem obstétrica.

\begin{abstract}
That was a convergent-care study, carried out in a maternity ward in the Southern Region of Brazil from April to May 2009, with the purpose to comprehend the meanings of premature mother-child skin-to-skin contact and relevant nursing contributions. Data were collected through participant observation and interviews involving nine mothers. Four categories were identified: a) predelivery orientation surrounding premature mother-child skin-to-skin contact; b) establishing premature mother-child skin-to-skin contact; c) meanings of premature mother-child skin-to-skin contact for the mother; and d) nursing contributions in establishing premature mother-child skinto-skin contact. It was concluded that the meanings of premature mother-child skin-to-skin contact attributed by these mothers is positive, and that nursing's contribution in establishing such contact is significant.
\end{abstract}

Key words: Parturition; Humanizing delivery; Breast feeding; Obstetrical nursing.

\section{RESUMEN}

Se trató de una investigación convergente asistencial, realizada en una maternidad de la Región Sur de Brasil, entre abril y mayo de 2009, cuyo objetivo es comprender el significado que el contacto precoz piel a piel, madre-hijo, tiene para el ser madre, y además, identificar las características de la creación de ese contacto, así como la contribución de la enfermería para esa relación. La recolección de los datos se hizo por medio de la observación participativa y de entrevistas con nueve madres, identificando cuatro categorías, a saber: a) las orientaciones acerca del contacto precoz piel a piel, madre-hijo, antes del nacimiento; b) la realización del contacto precoz piel a piel, madre-hijo; c) el significado que el contacto precoz piel a piel, madre-hijo, tiene para el ser madre, y d) las contribuciones de la enfermería para la realización del contacto precoz piel a piel, madre-hijo. Se concluye Que el significado del contacto precoz madre-hijo asignado por las madres es positivo, y la contribución de la enfermería para la realización de ese contacto es significativa. Descriptores: Parto; Parto humanizado; Lactancia materna; Enfermería obstétrica.

\footnotetext{
AUTOR CORRESPONDENTE Evanguelia Kotzias Atherino dos Santos. Universidade Federal de Santa Catarina, Departamento de Enfermagem.

Campus Universitário, Trindade. CEP 88040-970. Florianópolis, SC. E-mail: gregos@matriz.com.br
} 


\section{INTRODUÇÃO}

A promoção do contato pele-a-pele entre mãe-filho tem sido objeto de trabalhos científicos eue comprovam os benefícios fisiológicos e psicossociais, tanto para a saúde da mãe Quanto para a do recém-nascido ${ }^{(1-2)}$. A mesma deve ser estimulada desde os primeiros minutos de vida, necessita ser respeitado na sua individualidade e magia, Que envolve o binômio mãe-filho neste momento ${ }^{(2)}$.

Após o nascimento, o recém-nascido passa por uma fase denominada inatividade alerta, com duração média de euarenta minutos, na eual se preconiza a redução de procedimentos de rotina, em recém-nascido de baixo risco ${ }^{(1)}$ Nesta fase, o contato mãe-filho deve ser proporcionado, por tratar-se de um período de alerta Que serve para o reconhecimento das partes, ocorrendo a exploração do corpo da mãe pelo bebê( $\hat{}^{(1)}$.

O contato pele a pele mãe-filho deve iniciar imediatamente após o nascimento, ser contínuo, prolongado e estabelecido entre toda a mãe-filho saudáveis ${ }^{(2,3)}$. O contato pele-a-pele acalma o bebê e a mãe Que entram em sintonia única proporcionada por esse momento; auxilia na estabilização sanguínea, dos batimentos cardíacos e respiração da criança; reduz o choro e o estresse do recém-nascido com menor perda de energia e mantém o bebê aQuecido pela transmissão de calor de sua mãe $e^{(2-3)}$.

A amamentação se destaca como benefício do contato imediato ao tornar a suç̧ão eficiente e eficaz, aumenta a prevalência e duração da lactação, além de influenciar de forma positiva a relação mãe-filho ${ }^{(4)}$.

É salutar a recompensa Que a amamentação promove entre mãe e filho; o contato íntimo, freeüente e prolongado repercute no estreito e forte laço de união entre eles. Esta maior ligação mãefilho possibilita uma melhor compreensão das necessidades do bebê, o Que facilita o desempenho do papel de mãe e auxilia na transição gradual do bebê de dentro para fora da barriga $a^{(5)}$.

Comprovados os benefícios imunológicos, nutricionais e psicossociais da amamentação tanto para a mulher como para a criança, esforços têm sido empreendidos no sentido de promover, proteger e apoiar a prática do aleitamento materno, destacandose a implementação de políticas e ações para propiciar à criança o melhor início de vida possível( ${ }^{(6)}$. Insere-se neste contexto a Iniciativa Hospital Amigo da Criança (IHAC) lançada em 1991 e adotada por mais de 20.000 hospitais credenciados em mais de 156 países nos últimos 15 anos ${ }^{(7)}$.

Os "Dez Passos para o Sucesso no Aleitamento Materno" são a base da IHAC, da OMS/UNICEF, Que resumem as práticas necessárias a serem desenvolvidas nas maternidades, para o apoio ao aleitamento materno ${ }^{(8)}$. Dentre estas práticas, encontramos no Quarto passo: "Ajudar as mães a iniciar o aleitamento materno na primeira meia-hora após o nascimento"; a Qual é interpretada na atualidade pela OMS/UNICEF (2008) como "Colocar os bebês em contato pele-a-pele com suas mães imediatamente após o parto durante pelo menos uma hora e encorajar as mães a reconhecerem Quando seus bebês estão prontos para mamarem oferecendo ajuda, se necessário"(3).

No Brasil, de 1992 a 2004 foram credenciados 312 Hospitais Amigos da Criança, distribuídos em 24 estados e no Distrito Federal. Destes, 1 foi descredenciado e 10 foram desativados, sendo importante ressaltar que o Brasil é o único país no mundo a exigir o cumprimento desses requisitos no processo de credenciamento da $\mathrm{IHAC}^{(9)}$. Em Santa Catarina, existem atualmente 19 instituições credenciadas com o título, entre eles o Hospital Universitário Professor Polydoro Ernani de São Tiago, local de desenvolvimento deste estudo.

Para o sucesso do credenciamento, alguns fatores são fundamentais: o treinamento de toda a equipe Que trabalha com mães e bebês, a sensibilização do dirigente do hospital e das chefias de serviços da maternidade, pois é consenso Que rotinas e práticas hospitalares inadeQuadas podem acabar introduzindo o desmame precoce ${ }^{(9)}$.

Alguns hábitos, muito disseminados entre as maternidades, resultam na prorrogação do início do contato precoce mãe-filho. Dentre as rotinas dos cuidados imediatos ao recém-nascido encontramos: receber o neonato em posição Trendelemburg, secar, aspirar e avaliar o recém-nascido, realizar o exame físico seguido do banho de imersão, verificar os dados antropométricos e administrar medicamentos. A maior incidência de cesarianas, Que diminui o estado de alerta do bebê após o nascimento e a grande disseminação de analgesias de parto, Que resultam em sonolência materna; também dificultam a realização do contato precoce pele a pele mãe-filho(10-11).

Por outro lado, casos são descritos em Que o contato precoce não pode ser realizado imediatamente após o processo de parir, Quando a vitalidade do bebê encontra-se prejudicada e/ou momentos de fragilidade da mulher. $\mathrm{O}$ contato deve ser retomado assim Que mãe-filho estiverem em condições físicas e emocionais adęuadas e deve ser prolongado até Que seja suficiente para ambas as partes ${ }^{(3)}$.

Os profissionais de saúde possuem um papel determinante na realização do contato precoce pele a pele. Podem estimular e facilitar o contato com a prorrogação dos cuidados de rotina e suporte profissional ou trazer prejuízos pelo desrespeito aos mecanismos fisiológicos do recém-nascido e as evidências científicas sobre o aleitamento materno ${ }^{(1,8)}$.

Como suporte do profissional de saúde no momento do nascimento, é preciso oferecer tempo e ambiente tran\&uilo, auxiliar a mãe a posicionar-se confortavelmente, atentar para o estado de alerta e procura do bebê destacando os comportamentos positivos, favorecer a confiança materna e evitar manobras Que apressem o bebê na amamentação( ${ }^{(3)}$.

A partir da vivência das acadêmicas ao assistir diversas situações de parto e reconhecer o contato pele a pele precoce mãe-filho como um momento único e especial no processo de nascimento, instigadas em analisar esse momento por uma perspectiva materna pela necessidade de ouvir seus anseios e percepções sobre a importância desta vivência dentro de um Hospital Amigo da Criança, emergiu o interesse em pesquisar sobre o assunto e a pergunta de pesquisa: Qual o significado para as mães do contato pele-a-pele mãe-filho na primeira hora após o nascimento? Como ocorre o estabelecimento do contato pele-a-pele mãe-filho e de que modo a enfermagem pode contribuir?

Para tanto, traçamos como objetivos deste estudo: Compreender o significado do contato precoce pele-a-pele mãe-filho para o sermãe; Identificar características do estabelecimento do contato pelea-pele do binômio mãe-filho (tempo para início, duração e motivos para o término do contato) e as contribuições da enfermagem 
para este procedimento na primeira hora após o nascimento.

\section{MÉTODO}

Para o embasamento teórico-filosófico e metodológico deste estudo, optamos pela Teoria de Enfermagem Humanística de Paterson e Zderad. Nesta teoria, a enfermagem é compreendida como uma disciplina Que possibilita estabelecer uma relação intersubjetiva entre o ser cuidador e o ser que é cuidado, num determinado tempo e espaço vividos. É considerada essencialmente como um encontro vivido e dialogado entre seres humanos Que entram em relação contendo esta, todos os potenciais humanos e limitações de cada participante único ${ }^{(12-13)}$.

Portanto é uma teoria voltada para a vivência de cada indivíduo, preocupando-se em explorar as experiências humanas, dando ênfase ao significado da vida, à natureza do diálogo e à importância do campo perceptivo. Desta forma, cada mulher é considerada um ser único e traz consigo suas experiências, vivências e visão de mundo no momento do nascimento, tendo diferentes compreensões e significados ao primeiro contato com seu filho ${ }^{(14)}$.

Trata-se de um estudo descritivo, de natureza Qualitativa, tendo como referencial metodológico a Pesquisa Convergente-Assistencial (PCA) proposta por Trentini e Paim ${ }^{(15)}$. A opção por este referencial se fez a partir da necessidade sentida de articular teoria e prática na construção do conhecimento em Enfermagem uma vez Que, segundo suas autoras, esta modalidade de peseuisa procura manter em todas as fases do processo investigativo uma estreita relação com a prática assistencial, tendo como finalidade "encontrar alternativas para solucionar ou minimizar problemas, realizar mudanças e introduzir inovações na prática"(15).

Para a formulação da PCA, as autoras sugerem algumas fases a serem seguidas, como: fase de concepção, instrumentação, perscrutação, análise e interpretação. Cada uma dessas fases tem suas subdivisões, facilitando o seu desenvolvimento. É importante destacar Que estes passos não são, necessariamente, lineares, eles ocorreram concomitantemente durante a pesQuisa ${ }^{(15)}$.

A fase de concepção envolveu o início da pesQuisa, a concepção do tema, sua lapidação e foi desenvolvida com base na trajetória das pesquisadoras. Nesta fase a escolha do tema foi justificada, o problema de pesquisa foi definido e a busca pelo material teórico para suporte realizada ${ }^{(15)}$.

Seguiu-se a fase de instrumentação ao traçar os procedimentos metodológicos da pesquisa determinando o local, os participantes e as técnicas de obtenção e análise dos dados ${ }^{(15)}$.

O cenário escolhido foi o Centro Obstétrico e Unidade de Alojamento Conjunto da Maternidade do Hospital Universitário Professor Polydoro Ernani de São Thiago da Universidade Federal de Santa Catarina (HU/UFSC), Que presta assistência à saúde da população e desenvolve atividades de ensino, pesQuisa e extensão.

Os sujeitos significativos foram mulheres Que tiveram parto normal no Centro Obstétrico desta Maternidade e mantiveram contato pele a pele com seu filho na primeira hora após o parto, no período de abril e maio de 2009, com as Quais as acadêmicas tiveram contato direto durante o processo do trabalho de parto e pós-parto imediato podendo observar o período de contato pele-a-pele.

$\mathrm{O}$ número de sujeitos definiu-se à medida Que as informações foram sendo saturadas, ficando assim, condicionada à compreensão do fenômeno o que se deu ao completar nove sujeitos significativos, Que serão identificados através de letras, visando manter o sigilo da identidade das participantes

Durante a fase de perscrutação, a coleta e a análise dos dados ocorreram simultaneamente. No processo de apreensão foram realizadas entrevistas individuais gravadas (NE) com a utilização de um roteiro semi-estruturado, a fim de garantir o não distanciamento do tema a ser investigado e a aQuisição dos dados de forma integral; além de obter dados de observações (NO) e notas de diários (ND) no momento do primeiro contato pele a pele mãe-filho, no Centro Obstétrico ${ }^{(15)}$.

As entrevistas individuais ocorreram durante a permanência das mulheres no Alojamento Conjunto, ao aceitarem participar voluntariamente da pesquisa, após assinatura do Termo de Consentimento Livre e Esclarecido.

As fases de análise e interpretação compõem-se dos processos de apreensão, síntese, teorização e recontextualização; o Qual permitiu total domínio do tema em investigação, pela profunda familiaridade alcançada com as informações coletadas. Os dados obtidos em campo foram relacionados aos dados encontrados na literatura e a transferência dos resultados da pesQuisa pôde dar significado ao Que foi encontrado, justificando as mudanças no contato pele a pele mãe-filho, percebidos na equipe ${ }^{(15)}$.

O projeto foi aprovado pelo Comitê de Ética em Pesquisa com Seres Humanos da Universidade Federal de Santa Catarina, sob o número 064/09 colocar o número do $\mathrm{CAEE}$, respeitando as Questões éticas nos termos da Resolução 196/96 do Conselho Nacional de Saúde, posteriormente a autorização da instituição a ser pesquisada ${ }^{(16)}$.

\section{RESULTADOS E DISCUSSÃO}

O conteúdo das entrevistas realizadas, após o estabelecimento de uma relação através do encontro vivido e dialogado entre as autoras e as mulheres, foi possível identificar, como resultados, as seguintes categorias: Orientações acerca do contato pele-a-pele precoce mãe-filho antes do nascimento; Estabelecimento do contato pele-a-pele mãe-filho; Significado do contato pele-a-pele precoce mãe-filho para o ser-mãe e Contribuições da Enfermagem no estabelecimento do contato precoce pele-a-pele mãe-filho. Antes, porém, apresentamos as características sociodemográficas das mulheres entrevistadas (Quadro I).

Com base nos dados coletados das entrevistadas foi possível descrever um perfil baseado nas experiências individuais, Que formam as características sociodemográficas das mesmas. A idade variou entre 15 e 36 anos, sendo a média de idade das entrevistadas de 23 anos. Das nove entrevistadas apenas uma era casada, as demais mantinham união estável com seus companheiros. Sobre o nível de escolaridade das puérperas, encontramos diferenças consideráveis, sendo Que duas não haviam concluído o ensino fundamental, duas o haviam concluído, três possuíam o ensino médio incompleto, uma o ensino médio completo e uma havia cursado o ensino superior.

Quanto às vivências do ciclo gravídico-puerperal, observamos o planejamento da gestação em Quatro entrevistadas, este mesmo número foi identificado nas gestações não planejadas, acrescido de uma mulher Que não soube afirmar sobre o planejamento da 


\begin{tabular}{|c|c|c|c|c|}
\hline Puérpera & Idade & $\begin{array}{l}\text { Início do } \\
\text { contato }\end{array}$ & $\begin{array}{l}\text { Tempo de } \\
\text { contato }\end{array}$ & Motivo para o término do contato \\
\hline A & 15 & Imediato & $25^{\prime}$ & Mãe pronta para ir à sala de recuperação \\
\hline B & 17 & Imediato & $29^{\prime}$ & Mãe pediu Que o RN fosse retirado \\
\hline $\mathrm{C}$ & 22 & Imediato & $35^{\prime}$ & Pediatra retirou para examinar \\
\hline D & 25 & $4^{\prime}$ & $33^{\prime}$ & Mãe pronta para ir à sala de recuperação \\
\hline $\mathrm{E}$ & 36 & Imediato & $20^{\prime}$ & Pediatra retirou para examinar \\
\hline $\mathrm{F}$ & 23 & $3^{\prime}$ & $40^{\prime}$ & $\begin{array}{c}\text { Enfermagem retirou para os primeiros } \\
\text { cuidados }\end{array}$ \\
\hline G & 25 & $10^{\prime}$ & $26^{\prime}$ & Mãe pronta para ir à sala de recuperação \\
\hline $\mathrm{H}$ & 25 & Imediato & $35^{\circ}$ & $\begin{array}{c}\text { Enfermagem retirou para os primeiros } \\
\text { cuidados }\end{array}$ \\
\hline I & 29 & $3^{\prime}$ & $40^{\prime}$ & $\begin{array}{l}\text { Enfermagem retirou para os primeiros } \\
\text { cuidados }\end{array}$ \\
\hline
\end{tabular}

Quadro 1. Estabelecimento do contato pele-a-pele mãe-filho (tempo para início, duração e motivos para o término do contato). Florianópolis, 2009. mulheres mencionou ter recebido informações através de amigas e familiares Que já haviam passado pela experiência do contato pelea-pele mãe-filho, duas mulheres receberam a informação através da participação em grupos de gestantes e três mulheres foram informadas no momento da internação no Centro Obstétrico.

Fiz (pré-natal), mas não falaram não, eu fiquei sabendo por pessoas que já tinham ganho bebê aQui, mãe, amigas, parentes Que já tinham falado $[. .$. (Puérpera E) gestação, justificando Que não utilizava nenhuma forma de contracepção. Com relação à paridade, observamos Que a experiência do primeiro parto foi identificada em sete entrevistadas.

Os sentimentos Que permearam a descoberta da gestação foram descritos como felicidade em cinco mulheres entrevistadas, uma referiu sentir-se assustada, duas relataram ambos os sentimentos descritos anteriormente e uma apresentou em sua narrativa desespero.

Os diferentes sentimentos expressados podem ser explicados pelo referencial teórico, pelas diferentes relações interpessoais Que as mulheres estabelecem com suas famílias e comunidade. O tempo vivido decorrido até a aceitação da gestação é diferente pra cada mulher ${ }^{(12)}$.

Esses sentimentos ficam evidentes nos discursos a seguir:

Fiquei bem feliz, mas fiquei pensando se era bem isso mesmo Que eu Queria. Naquela hora, não fiquei em dúvida nem nada, mas na hora eu levei um choque sabe? Mas foi o primeiro mês, depois fieuei bem feliz. (Puérpera G)

Nossa... desespero né? No começo, até o Quarto mês eu não aceitava. Mas depois comecei a aceitar. (Puérpera C)

\section{Orientações acerca do contato pele-a-pele precoce mãe-filho antes do nascimento}

Na obtenção de informações na relação eu-nós, proposta por Paterson e Zderad, o indivíduo se relaciona com os outros, formando sua identidade através desta vivência, vindo a ser mais ${ }^{(12)}$. Todas as mulheres entrevistadas realizaram pré-natal e, nesta vivência, ao serem Questionadas sobre as informações Que receberam acerca do contato pele-a-pele, apenas duas referiram terem sido informadas da possibilidade de ter o bebê colocado em seu colo no momento do nascimento.

Fiz, umas cinco consultas. Ele (o médico) falou Que se fosse parto normal iam colocar o bebê em cima de mim pra ele sentir a minha pele (Puérpera D).

As informações sobre o contato pele-a-pele também estiveram presentes durante o itinerário percorrido na gestação. Uma das
Dentre os objetivos do pré-natal e grupos de gestantes está o favorecimento da compreensão de novas vivências pelas Quais a gestante e seus familiares irão passar, não só em relação à gestação, mas também ao parto e pós-parto ${ }^{(17-18)}$. É na ocasião do pré-natal Que surge a possibilidade de elucidar, pela primeira vez, a Questão do contato pele-a-pele mãe-filho.

\section{Estabelecimento do contato pele-a-pele mãe-filho}

No estabelecimento do contato pele-a-pele constatamos em cinco casos o contato imediato, nos demais, o início demorou de três a dez minutos, tendo como motivo a necessidade de atendimento ao recém-nascido devido a hipoatividade, cianose, baixa oxigenação ou ausência de choro.

O índice de Apgar manteve-se acima de sete no primeiro minuto e acima de oito no Quinto minuto em todos os nascimentos, não havendo necessidade de intervenções invasivas. $\mathrm{O}$ atendimento limitou-se a estimulação tátil e aQuecimento do recém-nascido.

Segundo a UNICEF/OMS, em sua atual interpretação sobre o Quarto passo dos "Dez Passos para o Sucesso do Aleitamento Materno", os bebês devem ser colocados junto à mãe de forma contínua, nos primeiros minutos de vida, encorajar as mães no reconhecimento de seus bebês Quanto à amamentação, sendo preconizado o contato continuado por pelo menos uma hora. Identificamos neste estudo Que nenhum contato atingiu o tempo preconizado $^{(3)}$.

Os motivos para o término do contato variam desde o pedido da mãe até a solicitação da equipe multidisciplinar para o início dos cuidados a serem prestados ao bebê, o Qual foi observado na maior parte das vezes. Percebemos Que esta remoção tem como fundamento a ansiedade da equipe e a pressa em realizar os primeiros cuidados ao recém-nascido, principalmente Quando os nascimentos ocorrem no final do turno ou Quando há sobrecarga de trabalho no setor.

Salientamos a redução das separações desnecessárias entre o binômio mãe-filho com a diminuição dos procedimentos realizados no pós-parto imediato, ao estritamente necessário, Quando se tratar de um bebê de baixo risco(l).

Durante a realização de uma reunião com a equipe de enfermagem do setor, observamos, como resultado de nossa 
presença e intervenção no desenvolvimento da PCA, a equipe levantar a possibilidade de transferir a realização do banho para a Unidade de Alojamento Conjunto. Esta prática pode diminuir a ansiedade dos profissionais e facilitar a promoção e a maior duração do contato pele-a-pele mãe-filho. $\mathrm{O}$ banho do recém-nascido deve ser realizado de 2 a 6 horas após o nascimento, Quando a temperatura encontra-se estável ${ }^{(19)}$.

\section{Significado do contato pele-a-pele precoce mãe-filho para o ser-mãe}

As entrevistadas descrevem o significado e a importância do contato pele-a-pele mãe-filho em discursos bastante heterogêneos, Que abrangeram desde a naturalidade do momento, a felicidade, até o alívio e a força proporcionados pelo contato; evidenciado no discurso a seguir.

Aí vem uma sensação boa, um sentimento de alívio, e uma felicidade. (...) é uma coisa muito natural, assim é natural. (Puérpera G)

Esta heterogeneidade pode estar relacionada às diferentes vivências/experiências pessoais de cada indivíduo, levando a uma singularidade do momento, inclusive para mulheres Que já haviam passado pela experiência de descobrir-se mãe ${ }^{(12)}$.

Através dos discursos das mulheres podemos perceber o contato pele-a-pele como um momento único, em Que acontece o primeiro reconhecimento do bebê e Que a mulher pode pela primeira vez, apreciar o seu filho e vivenciar fortes sentimentos de emoção, referenciados de diferentes maneiras. $\mathrm{O}$ momento do nascimento como um encontro íntimo e profundo entre mãe e filho, Que traduz toda a espera decorrida da gestação ${ }^{(20)}$.

[...] tava no meu instinto, acho Que isso é mesmo instinto de cuidar, analisar, ver os detalhes, a mãozinha, a unha Que já era grande, o cabelinho, ver Que ele me procurava com os olhos Quando eu falava, ver Que primeiro ele abriu um olhinho[...] (Puérpera I )

O momento do nascimento gera grande expectativa na mãe, não só durante o trabalho de parto e parto, mas durante toda a gestação, Quando ela se pergunta se o bebê Que está por vir será da forma Que ela imagina(2). É neste primeiro contato Que a mulher tem a oportunidade de ver, por si própria e não por relato dos profissionais, os detalhes de seus bebês, já buscando encontrar semelhanças deste novo ser com seus familiares ${ }^{(22-23)}$.

A realização do contato pele-a-pele precoce mãe-filho "transmite para mãe tranqüilidade e segurança, pois neste momento ela pode sentir, ver, segurar o seu bebê, e toda a ansiedade e curiosidade pode ser sanada"(20).

O sentimento de alívio observado em todas as mulheres após o nascimento de seu bebê é mais evidente após o início do contato pele-a-pele e tem relação com o efeito fisiológico da ocitocina enquanto antagonista da adrenalina, o que reduz a ansiedade materna e proporciona alívio ${ }^{(24)}$.

(Significou) força. Foi muito importante, porQue no momento Que eu tava sentindo a dor assim, eu pensei em desistir, mas no momento que eu vi ele valeu a pena. (Puérpera D)

Algumas mulheres demonstraram dificuldade em expressar o Que havia significado esse momento, como em:

Não sei, não caiu a ficha ainda... é muito bom né? Dá pra sentir ela assim... (Puérpera C)

Sei lá, não tem explicação, é muito bom, muito bom (Puérpera D)

Todas as mulheres consideraram Que o momento para início do contato pele-a-pele foi o mais propício, sendo descrito como ideal. Somente aspectos positivos são encontrados, nos discursos das mulheres entrevistadas.

Ele nasceu, aí levaram pra dentro e trouxeram depois, ai ficou, bem a vontade [... Fo Fo (o melhor momento), bem interessante. (Puérpera G)

Entre as mulheres Que o contato não ocorreu de forma imediata após o nascimento, não são percebidos aspectos negativos Quanto à assistência prestada pelos profissionais de saúde ao recém-nascido, anteriormente ao contato pele-a-pele.

\section{Contribuições da Enfermagem no estabelecimento do contato precoce pele-a-pele mãe-filho}

No Que diz respeito às contribuições da enfermagem no estabelecimento do contato pele-a-pele, todas as mulheres consideram o atendimento eficaz. Ao serem Questionadas sobre o Que poderia ser feito para a melhora desta assistência, oito disseram ser suficiente e não souberam colocar como poderia ter sido de melhor maneira. Uma delas justificou não ter informações sobre seus direitos, a fim de avaliar o atendimento.

[...] elas auxiliam, ajudam a colocar no peito, elas conversam, ficam ali te dando carinho, te dando apoio o tempo todo, é importante demais pra mim Que já tenho (filho), imagina pra Quem tem o primeiro e está meio perdida sem saber o Que fazer. (Puérpera F)

O apoio da equipe de enfermagem é importante neste momento de transição, em Que a mulher passa a ser mãe e nutriz. ${ }^{(25)}$ É a enfermagem Que tem a oportunidade de proporcionar o início do contato e de auxiliar a mulher neste primeiro reconhecimento de mãe-filho, agora fora do ventre ${ }^{(26)}$.

Fui acolhida, tu te sente muito bem, muito à vontade, foi ótimo. Me ajudaram desde o começo, lá no trabalho de parto, fazendo massagem, estimulando os exercícios [...] Toda a equipe foi maravilhosa comigo. (Puérpera I)

A importância da presença da equipe de enfermagem no momento em Que a mulher se torna mãe proporciona mais segurança e liberdade para a mulher solicitar ajuda, sempre Que necessário ${ }^{(27)}$.

Outra mudança percebida na prática assistencial da equipe de enfermagem, como resultado da PCA, foi identificada após 
conversas informais e reuniões, ao apresentar a importância e instigar uma reflexão da equipe, sobre o contato precoce pele-a-pele. A equipe demonstrou-se mais atenta durante a assistência prestada ao binômio no estabelecimento do contato pele-a-pele mãe-filho, incluindo este contato como uma rotina no setor, devendo ser respeitado sempre Que possível.

\section{CONSIDERAÇÕES FINAIS}

A realização deste estudo possibilitou, de um lado, compreender o significado do contato precoce pele-a-pele mãe-filho para o sermãe evidenciando a importância dessa vivência de forma plena, ainda na sala de parto. Um momento natural, belo e exclusivo, de reconhecimento familiar, permeado de significados e benefícios para os dois seres ali envolvidos: o ser-mãe e o ser-filho.

Por outro lado, permitiu identificar o modo como é estabelecido o contato pele-a-pele do binômio mãe-filho (tempo para início, duração, motivos para o término do contato) e as contribuições da Enfermagem para este procedimento na primeira hora após o nascimento.

No estabelecimento do contato pele-a-pele precoce mãe-filho houve o cumprimento do Quarto passo nos "Dez Passos para o Sucesso do Aleitamento Materno"(3) da OMS/UNICEF, porém o tempo não alcançou mais de Quarenta minutos, enquanto o preconizado seria de uma hora. Isto demonstra um distanciamento entre o modelo proposto e as práticas atuais consolidadas no cotidiano dos profissionais de saúde, atuantes na maternidade em Questão. Apesar destes fatos identificados a avaliação da atuação da equipe de enfermagem sempre foi positiva pelas mulheres entrevistadas.

Como proposta da PCA, as pesquisadoras foram integrantes da equipe de enfermagem, o Que possibilitou perceber as dificuldades inerentes à prática assistencial. Uma relação por vezes conflituosa, ao desenvolver suas atividades com profissionais formados para atuar de diferentes maneiras no evento do nascimento, com práticas intervencionistas Que dificultam o contato pele-a-pele precoce mãefilho. O diálogo com a equipe multidisciplinar foi necessário para Que a coleta de dados pudesse ser realizada e permitiu reflexões da equipe, Que resultaram em modificações sobre a assistência prestada ao binômio mãe-filho, no momento do nascimento.

O suporte profissional prestado no estabelecimento do contato pele-a-pele precoce mãe-filho, a promoção de ações de cuidado no ambiente envolvido e interação com o binômio visando à realização mínima de intervenções e auxílio no reconhecimento mãe-filho, podem ser o caminho para alcançar aquilo Que se recomenda na atualidade e Que possui evidente importância materna.

Acreditamos Que a educação continuada com os profissionais de saúde e a renovação dos saberes, pode resultar na melhoria da Qualidade da assistência prestada, além do reconhecimento e consolidação do exercício da profissão de enfermagem.

\section{REFERÊNCIAS}

1. Cruz DCS, Sumam NS, Spíndola T. Os cuidados imediatos prestados ao recém-nascido e a promoção do vínculo mãebebê. Rev Esc Enferm USP 2007; 41 (4): 690-7.

2. Almeida EA, Martins Filho I. O contato precoce mãe-filho e sua contribuição para o sucesso do aleitamento materno. Rev Ciên Méd 2004; 13(4): 381-8.

3. World Health Organization. Baby friendly hospital initiative, revised, updated and expanded for integrate care, Section I, Background and Implementation, Preliminary VersionGeneve: WHO; 2006.

4. Saadeh R, Akré L. Ten steps to successful breastfeeding: a summary of the rationale and scientific evidence. Birth 1996.

5. Lana APB. O livro de estímulo à amamentação. São Paulo: Atheneu; 2001.

6. Monteiro ICS, Nakano MAS, Gomes FA. Amamentação precoce na primeira meia hora de vida da criança. Rev Enferm UERJ 2006; 14(2): 202-7.

7. IBFAN Brasil. Cursos. Jundiaí: IBFAN; 2008 [citado em 2009 Mar 08]. Disponível em: http://www.ibfan.org.br/cursos/ detalhes.php?id $=6$

8. Organização Panamericana de Saúde. Evidências científicas dos dez passos para o sucesso do aleitamento materno. Brasília: OPAS; 2001.

9. Araújo MFM, Schmitz BAS. Doze anos de evolução da Iniciativa Hospital Amigo da Criança no Brasil. Rev Panam Salud Pública 2007; 22(2): 91-9.

10. Venâncio SI. Dificuldades para o estabelecimento da amamentação: o papel das práticas assistenciais das maternidades. J Pediatria 2003; 79(1): 1-12.

I I. Carvalhares MABL, Corrêa CRH. Identificação de dificuldades no início do aleitamento materno mediante aplicação de protocolo. J Pediatria 2003; 79(1): 13-20.

12. Paterson JG, Zderad LT. Humanistic nursing. New York: National League for Nursing; 1988.

13. Praeger SG, Hogarth CR. Josephine E. Paterson e Loretta T. Zderad. In: George, IB, organizador. Teorias de enfermagem: os fundamentos para a prática profissional. Porto Alegre: Artes Médicas; 1993. p. 243-53.

14. Oliveira ME, Brüggemann OM, Fenilli RM. A Teoria humanística de Paterson e Zderad. In: Oliveira ME, Brüggemann OM, organizadoras. Cuidado humanizado: possibilidades e desafios a prática da enfermagem. Florianópolis: Cidade Futura; 2003. p. I1-33.

15. Trentini M, Paim L. Pesquisa convergente-assistencial: um desenho Que une o fazer e o pensar na prática assistencial em saúde-enfermagem. 2a ed. Florianópolis: Insular; 2004.

16. Ministério da Saúde (BR). Conselho Nacional de Saúde. Resolução no 196, de 10 de outubro de 1996. Dispõe sobre diretrizes e normas regulamentadoras de pesQuisas envolvendo seres humanos. Brasília: Ministério da Saúde; 1996.

17. Zampieri MFM. Pré-natal humanizado: um olhar para além das divergências e congruências. Florianópolis: Universidade Federal de Santa Catarina, Programa de Pós-Graduação em Enfermagem; 2004.

18. Lunardi Vl, Bulhosa MS. A influência da iniciativa hospital amigo da criança na amamentação. Rev Bras Enferm 2004; 57(6): 683-6.

19. World Health Organization. Essential Newborn Care and Breastfeeding -Training modules. WHO Regional Office for Europe, 2002. [citado em: 2009 Jun 12]. Disponível em: http:/ 
/www.euro.who.int/document/e79227.pdf

20. Barbosa V, Orlandi FS, Dupas G. Aleitamento materno na sala de parto: a experiência da puérpera. In: Anais do $1^{\circ}$ Congresso Sul Brasileiro de Aleitamento Materno e bancos de Leite Humano; 2008. Disponível em: http://www.furb.br/formularios/ aleitamento/anais/als/art_als_02.pdf.

21. Alves AMA, Santos IMM. Quando o bebê que chega não é o sonhado. In: Figueiredo NMA, organizadora. Ensinando a cuidar da mulher, do homem e do recém nascido. São Caetano do Sul: Yendis; 2005. p. 225-39.

22. Ávila AMA, Mello AV. O primeiro amor. In Anais do $I^{\circ}$ Congresso Sul Brasileiro de Aleitamento Materno e bancos de Leite Humano; 2008. Disponível em: http://www.furb.br/ formularios/aleitamento/anais/als/art_als_05.pdf.

23. Gasperi BI, Martins FE, Rosa R. Primeiros Laços: aproximações entre mãe e filho no momento do nascimento [monografia].
Florianópolis: Curso de Graduação em Enfermagem, Universidade Federal de Santa Catarina; 2008.

24. Anderson GC, Moore E, Hepworth J, Bergman N. Early skinto-skin contact for mothers and their healthy newborn infants. Cochrane Database Syst Rev 2003. [citado em 2009 Jun5]. Available from: http://cochrane.bireme.br/main.php?lang=.

25. Monteiro ICS. Contato precoce e amamentação em sala de parto na perspectiva da mulher [dissertação]. Ribeirão Preto: Escola de Enfermagem de Ribeirão Preto, Universidade de São Paulo; 2006.

26. Merighi MAB, Gonçalves R, Rodrigues, IG. Vivenciando o período puerperal: uma abordagem compreensiva da Fenomenologia Social. Rev Bras Enferm 2006; 59(6): 775-9.

27. Sonego I, Van Der Sand ICP, Almeida AM, Gomes FM. Experiência do desmame em mulheres de uma mesma família. Rev Esc Enferm USP 2004; 38(1): 34 I-9. 